\title{
Where Do they Go, Whom Do they Consult and Why? Health Seeking Behaviors of Pregnant Women Among Fishermen Community in Rural Sylhet
}

\author{
Md. Abul Hossen ${ }^{1}$, Faisal Ahmmed ${ }^{2, *}$ \\ ${ }^{1}$ Department of Social Work, Jagannath University, Bangladesh \\ ${ }^{2}$ Department of Social Work, Shahjalal University of Science and Technology, Bangladesh \\ *Corresponding Author: fahmmedsust@yahoo.com
}

\begin{abstract}
The situation of pregnancy and childbirth related morbidity and mortality is worse in Bangladesh because of low utilization of maternal health services. This situation is much more vulnerable among fishermen community than that of the majority community of Bangladesh due to their marginalized and disadvantaged status. Based on a qualitative investigation this article investigates the determinants of health seeking behavior and their influence on health service utilization among the pregnant women of fishermen community in Sylhet region. The findings reveal that women's culturally and socially determined roles greatly impair their health and play an important role in health seeking behavior through a complex web of social, economic, religious, cultural and behavioral interrelationships and synergies that pervade every aspect of their life. It also reveals that only infrastructural development cannot ensure the success in health sector, changing people's behavior through health promotion and building awareness is the key to bring success in this area.
\end{abstract}

Keywords Health Seeking Behavior, Pregnant, Woman and Fishermen

\section{Introduction}

The use of health services is related to availability, quality and cost of services as well as the social structures, religious faith, health beliefs and personal characteristics of the users. According to the World Health Organization (WHO), over half a million women succumbed to death each year from complications of pregnancy or childbirth. The situation of pregnancy and childbirth related morbidity and mortality is worse in Bangladesh because of low utilization of maternal health services (Nuruzzaman, 2009). The reduction in levels of maternal mortality and improvement of maternal health has been central policy goals since the inception of Fourth Population and Health Program in Bangladesh in 1992. Efforts to address these issues have gained considerable momentum with the formulation of the National Strategy for Maternal Health (Ministry of Health and Family Welfare, 2001) and further strengthened by establishing a National Steering Committee (NSC) to review the progress (Nath, 2008). This strategy is predicated on the 'Three Delays Causal Framework' that affects safe motherhood service utilization and outcomes: delays in making the decision to seek care, delays in reaching a medical facility and delays in receiving adequate treatment or management at the facility (Thaddeus and Maine, 1994) and emphasizes the provision of emergency obstetric care to resolve this endemic problem.

Maternal mortality is one of the biggest challenges in Bangladesh's health sectors because the country has one of the highest maternal mortality rates in the world. About 15,000 mothers die annually at the time of delivery, with 3 maternal mortality per 1,000 live births and 7,000 infants die everyday (Nath, 2008). In the case of maternal mortality, 16-25 per cent of deaths are due to septic abortions, 20 per cent due to eclampsia, 5-10 per cent due to postpartum sepsis, and another 5-10 per cent of women die due to tetanus (Hossen, 2010). The international Centre for Diarrhoeal Research (ICDDR'B), Bangladesh reported in 2002 that 50 per cent of pregnant women are underweight, and the average weight of women is only $42 \mathrm{~kg}$. About 70 per cent of women are anaemic, and 43 per cent have iodine deficiency and a good many most likely have zinc deficiency (ICDDRB, 2002). Though the maternal mortality ratio in Bangladesh has declined from more than 600 in 1980 to 322 in 2004, it is still one of the highest in the world. Pregnancy and delivery related deaths account for 20 percent of the death in women of reproductive age. The unavailability of trained service providers, low utilization of services by pregnant women, along with the infrastructure difficulties, together contribute to the high rate of maternal deaths in Bangladesh. As well, 
the utilization of maternity care provided by trained professionals during and after delivery is alarmingly low in Bangladesh. Although there is no available data on Sylhet region on this issue, it is highly likely that as a marginalized and disadvantaged who lives in strict religious region of Bangladesh, their situation is much more vulnerable than that of the other region of Bangladesh. While there have been some improvements in the recent years, about half of the pregnant women still do not seek any antenatal care. Similarly, women's awareness of potentially life-threatening conditions during pregnancy, delivery and after delivery is comparatively lower in Bangladesh than many countries. Everyday on an average 32 mothers die during the delivery. About 70 percent of pregnant women do not have access in emergency pregnancy support and 78 percent of the mothers mortality is caused by this reason (Ministry of Health Family Planning, 2009).

There exists urban-rural discrepancy in maternal mortality and the statistics is skewed in relatively 'socially conservative' districts. For instance, maternal mortality is higher in Sylhet than any areas in Bangladesh (Prothom Alo, Dec, 19, 2009). Bangladesh Demographic and Health Survey (BDHS) 2007 reveals that at national level 85 percent delivery takes place at home and only 18 percent women receive support from health worker. This survey mentioned that this number is 5 percent low in Sylhet division. Only 10 per cent of pregnant women in Sylhet division give birth in different government and private health centers. Similarly, the government statistics indicate that at national level 46 percent of rural women seek health support during pregnancy whereas it is much lower in rural parts of Sylhet division (Hossen \& Wessthues 2011). It is customary in Sylhet that people avoid rural health and family planning workers, union heath and family welfare centers, satellite clinics or any other health facility for seeking support during pregnancy and safe delivery (Osmani, 2010).

There are several social, religious and economic barriers that prevent pregnant women from seeking services from health facilities. The conventional economic views promotes that the government health facilities located in rural areas provide free antenatal care (ANC), delivery and postnatal care (PNC) services, yet the cost related to medicines, transportation and surgical operations in the case of complications discourages poor women to seek services from these facilities (Hossen \& Westhues, 2011). This economic view may explain part of the puzzle yet social stigma generated through patriarchal structure deserves some credit. For instance, a prevalent perception among male is that pregnancy is a natural process for women and it will pass normally and thus no extra care and support is needed in this phase of life. Men (and sometimes along with women) promote superstitions like not taking much food during pregnancy arguing that extra feeding shall increase the growth of the fetus and will affect normal delivery (Hossen \& Westhues, 2011).
The disarray in health seeking behavior is strongly associated with inferior status of girls and women in Bangladesh. This is mainly due to entrenched dysfunctional gender relations brought about by dated social and cultural practices and is reinforced by literalist interpretations of religious tomes, especially the Qur-an and other similar texts. Under the umbrella of purdah and the sometimes self-serving interpretation of the Quoran by men, certain values and practices of Bangladesh society have made applicable to the daily living experiences of the rural poor women (Reza and Ahmmed, 2009). These women have to exist in an environment that is marked by a "forced poverty of social relationships" (Reza and Ahmmed, 2009) that requires them to be confined to their living quarters free from exposure to outsiders, mainly males. This is done, so she is taught, in order to preserve their modesty vis-a-vis the outside world (Kibria, 1995). Overriding all of these, the poor rural woman is treated as if her body and her future are not hers to own and manage. Naturally, this has a trickle down effect on any health-seeking behavior of women. Highly likely that this process makes the women vulnerable and naturally her physical and other wellbeing goes to the hand of male family members or counterparts like the majority people in Bangladesh (Osmani, 2010). Though few researches addressed overall health behavior of Bangladeshi people, data on health behavior and the nature of access to health services during pregnancy is not articulated separately that could help us to understand the issue in details. From above background, based on first hand data this article aims to investigate the determinants of health seeking behavior and their influence on health service utilization of rural Sylhet region particularly among fishermen community who are known as disadvantaged section of population, and to facilitate the health policy planning process by providing evidence based information to the local government and health care providers.

\section{Methodology}

With the objectives of an in-depth exploration on health seeking behavior of pregnant women among selected fishermen villages, the research project used a qualitative design. The goal of the qualitative design is to represent the participants' reality as faithfully as possible from their points of view (Morgan and Kunkel, 2001). The qualitative design could help the researchers to gather information through the use of multiple methods of data collection that includes, interview, conversation and observation. Three villages namely Gouripur, Pirpur, and Haiderpur of Tuker Bazar Union under Sylhet sadar upozilla was selected purposively. The study found sixteen pregnant women living in the selected villages who were regarded as the population of the study and all of them were interviewed as respondents of the research.

A standardized interview protocol was developed and 
applied to collect data from pregnant women. The protocol emphasized mainly open-ended questions covering all aspects of the research objectives. Corresponding questions were developed to explore the detailed information on issues such as maternal health, rights and access to maternal health. Extensive field notes were collected through observation and informal discussion. The successful collection of qualitative data depends largely on the mutual understanding between the researchers and the participants. The researchers and their assistants spent a fair amount of time at the research sites to develop rapport with the participants so that information can be gathered in a free, friendly, and trustworthy manner. None of the individuals is identified in the narratives. Instead, generic and anonymous terms have been used to ensure confidentiality. Only the researchers and their assistants had the access the interview and discussion instruments and are destroyed after completion of project.

\section{Major Findings}

\section{Present Age and age at Marriage}

As the study conducted on pregnant women and considered only pregnant women as participants, we found all participants within the age of fertility ranging from eighteen to thirty seven. Early marriage and becoming mother at tender age among the women are common in Bangladesh and the study found the same reality among its participants, highest number of whom got married at the age group between eighteen and twenty two. Marriage before twenty was common among them. In Bangladesh the legal age of marriage for women is twenty, but out of sixteen participants the study found seven women who became mother before twenty years of age.

\section{Economic Condition of participant's family}

We conducted this study on the fishermen community most of whom survival on fishing on the open water. Fishing is a traditional livelihood here in Bangladesh in which a group of people engage ancestrally. Within the social structure of Bangladesh this people belongs to low status and are subordinated by many means mainly because of their occupation. Though the low-cast Hindu people are engaged in this occupation at large scale, few Muslims are also engaged in this occupation ancestrally. The earning and economic condition of fishermen is depends upon the sector in which the person is engaged. Among them who are engaged in fishing directly, their earning is lower than those who are engaged in fish trading. On the other hand, all fish traders are not good earners. As the access to water bodies are shrinking due to its management system as well as due to the decreased trend of water bodies and the disappearance of fish verities, this occupation is loosing its attraction. Many fishermen community members are changing their ancestral occupation because of those reasons. The concentration of fishermen community is located closer to urban centers where they have multiple opportunities to get access to job market other than fishing. All of those issues were strongly prevalent in our study area. Husbands of our respondents were engaged in multiple activities as they have good connectivity with urban centers. Few are engaged in business and few are working as motor drivers, rest of them also has their own CNG-run auto rickshaws. These groups have good earning that those who engaged in fishing of fish trading. However, most of the community people are still depends upon fishing and fishing related occupation. That is why the economic condition of the study community can be marked as not good as their income can not support for fulfilling their basic needs.

\section{Physical condition and complicacies during pregnancy}

As most of the respondents have taken their first child at early age, it was common to experience multiple complicacies. Most of the participants who are second time pregnant reported that they face different kinds of health risks in different phases of their pregnancy during the first issue. Their present pregnancy is also associated with various types of complicacies. Participants reported suffering from a range of illnesses and conditions. Many of the physical health problems they identified were common low level health problems during pregnancy such as headaches, bodily pains, tiredness, fever, general weakness. One of our participants who was thirty years of age and was pregnant for the seventh time mentioned:

"I feel bad during my pregnancy; I do not get energy to work and sometimes my eyesight becomes hazy. I can not move freely. My skin is infected. Headache and vomiting is also frequent."

Another echoed the same condition:

"I am pregnant still I have to work from dawn to dusk. Sometimes, I feel very weakness. In the afternoon I feel fever and headache too."

\section{Perception on health care during pregnancy}

Though most of the participants were suffering from multiple physical complicacies during their pregnancy, we found only one forth of them who perceived that any complicacy related to pregnancy should be addressed by medical doctors. They do not believe in regular check-up so that action may be undertaken at the time of any emergency. One of our participant's views can be observed here:

"During my previous pregnancy I have observed that help of medical doctor does not work always to minimize regular complicacies. I took medicine for controlling vomiting and headache but the efforts were worthless, I spent money only. That is why this time I am not going to medical doctor regularly for check-up or for minor complicacies. I shall go to hospital in case of emergency."

Rest of the participants believes that pregnancy is a natural 
biological process and the experience they have gained by observing from their mother, neighbor or other relatives can be enough to solve any problem that might emerge down the road. One of our participants can be presented in this connection:

"My mother in-law and elder sister told me that there are complicacies common during pregnancy. These are natural and shall be cured automatically. They said it mentioning their personal experience. They suggested me for taking additional food, avoiding laborious work, careful movement, taking rest and regular sleeping. If a pregnant woman follows those regulations she will be able to encounter any health complicacies going hospital for treatment is not effective. Thus, I do not go to hospital or clinic for medical support."

\section{Types of support rely on during pregnancy related complicacies}

Education, economic condition, family norms and socio-cultural perceptions affects participant's trust and comfort upon supports for addressing complicacies during pregnancy. Among participants who had some level of education showed their trust and interest on medical professionals. They believe in the medical support for the treatment of any pregnancy related complicacies. This group are also financially solvent that other participants who have fascination on traditional supports. Cost of medical support is another important factor which is directly linked with the economic capability of participant's family. Thus, participants who have ability to afford medical const, only they are found to be fascinated towards the support of medical doctors. Personal relationship with care givers was another significant factor to choose support at the time of complicacies. We found few pregnant women who prefer to receive support from both medical doctor and traditional birth attendants (TBAs). As TBAs are their community people and they do have easy access with minimum cost some pregnant women make regular contact with them and follow their guidelines during the whole period of pregnancy. This group primarily tries to resolve all problems by TBAs and once it does not work, they go to hospital/clinic for medical support. Though the studied community is located very closer distance to divisional headquarters with available modern medical facilities; about half of our participants shoed their disinterest to seek support from medical professional. Instead of that they prefer to resolve problems traditionally based on the suggestions of senior women in the community and they have frequent visit to traditional healers and religious clergymen for resolving pregnancy related physical complicacies.

\section{Whether the participants consult medical professionals regularly}

Though regular medical check-up is essential for reducing health risk of pregnant mother and there are camping on its importance; we found only two participants who regularly visit hospital or clinic for medical check-up and follow the guideline of care givers. These two women were educated and were conscious about their health and they had idea about the importance of regular check-up during pregnancy. Few visit hospital or clinic if there is complicacy and they do not feel that regular check-up is needed during pregnancy. One of our participants viewed,

"I did not go to hospital or visited physician. My pregnancy crossed seven month and did not feel any physical problem. So why should I go there for spending money? If something goes wrong, then I shall go. My mother in-law and other senior women in my family suggested that I should not go there for check-up regularly as it does not have any importance. We try to follow the suggestions of our seniors. Sometimes our husbands bring medicine from medicine vendors and we get cured."

Another participant told that,

"My mother in-law is an experienced woman, people seek her suggestions. She told me that pregnancy period goes with some complicacies like vomiting, physical weakness, back pain, headache, reluctance towards food etc. So you should not be worried. Everything will be fine automatically. Visiting hospital or clinic is not needed. That is why I don't go for regular check-up."

Daily chores of household preclude participants to go to hospital for consultation. Since some of them do not have any extra hand to help so they compelled to stay home to manage family affairs. Another participants mentioned:

"I need to go to clinic sometimes but I am so much busy at home that I could not manage time."

\section{Types of Activities that Participants Perform regularly}

All of our participants were found to be active in daily household chores during their pregnancy. It is mainly because of their life style. In rural areas almost all women have to perform some family activities regularly like cooking, cleaning home and cloths. Cooking food is considered as negligible work though the process of cooking is not an easy task there in rural areas. Collecting and processing of fire wood are laborious and in most cases that have to perform by women. Colleting water for cooking is another assignment that require vigorous labor as women are usually responsible to collect water both for cooking and drinking. Moving water pots from one place another place and fetching water from the distance is risky during pregnancy. As most of our participants and their family view pregnancy as natural and easy-going process, majority of perform all possible family activities by themselves. One of them viewed,

\footnotetext{
"Cooking, washing and cleaning etc are regular
} 
activities of our family and I prefer to do all those tasks regularly by myself. If I don't do who else come to help me? We don't have enough money to hire a helper. I have to take care of my children I do not feel any difficulty for this."

Few mentioned that despite their physical vulnerability, they have to perform all household activities. If they show disinterest, their mother in-laws call their names and abuse verbally. One told,

"I am sick, but I have to do all household activities. If I fail to do, my mother in-law abuses me verbally and creates uncomfortable family environment."

Another participant opined that,

"I will have to perform my own family activities. These are my work, as I do have nobody to help, I will have to do everything. I have done same activities during my previous two pregnancies. Sometimes I feel bad but there is no way to escape. My family will become mal-functional if I keep quite."

\section{Sources of supports during pregnancy}

We also found a few number of fortunate participants who receive supports from family members i.e. mother in-law, sister in-law, brother in-law, mother, sister, own children and husband who share some activities like collecting water, cleaning home and washing cloths. But they did not get this support on a regular basis. One of our participant's anecdotes can depict the reality,

"My husband works in fish market as fish trader and he has to engage there until mid-night. He is caring but difficult for him to support me. However, I get his assistance occasionally during his off-days. He helps me in collecting water from tube well. Sometimes he process fire woods and clean yard."

Some participant complaint about their husband as they were disinterested in listening their wives complain because of their hectic life schedule. One of our participants told that,

"My husband is busy with earning activity, he does not have time and I do not get opportunity to share my problems with him and he is not interested to listen to my physical complicacies."

However, few of our participants informed that their husband accompany them during visits for seeking health care and give money if it is essential. They also get opportunity to participate in decision making process for receiving health services. But according to the findings of the research most of the women are dominated by the members of their husband's family and decision on receiving health support is made by husband's family members i.e. mother in-law, sister in-law, or elder brother of husband. One of our participants viewed,

"Sometimes I fill bad and want to go to health centers. But it is not possible if my mother in-law and elder sister of my husband does not allow me. I have no personal freedom of movement and have to depend upon the will of the family members of my husband. My husband suggested me to follow the advices of my mother in-law at any purpose. Once I told them to arrange medical check-up for me; but I was abused verbally both by my mother in-law and husband. My mother in-law told that I have crossed my limit and I should not express my need; they will make decision what to do."

\section{Knowledge about Harmful Affects of Some Laborious Jobs during Pregnancy}

Except few exceptions, our participants had a good understanding on the harmful affects of laborious jobs during pregnancy. Participants listed some of laborious jobs like collecting water from distant place and moving packages of crops one place to another place that they viewed as risky during pregnancy. They told that thy have learnt from care givers that laborious works during pregnancy results multiple affects like the death of child, pre-mature birth, risky delivery and severe health risks of mother. One of the participants viewed,

"One of my babies was died at the time of my five month pregnancy. Due to this accident my physical condition experienced serious risk and I was about to die. Physicians identified that it happened as a result of my regular laborious life-style. I had to do all laborious jobs during the whole period of my pregnancy."

Interestingly, despite having knowledge and about the harmful affects of laborious jobs, pregnant women in our studied villages usually do not maintain health laws and are engaged in laborious jobs like cooking, collecting water, cleaning houses etc. We found two of our participants had different understanding, they viewed that anything can be done at the time of pregnancy and no one should give up regular activities that they are used to perform. According to them changing lifestyle due to pregnancy does not make any sense, rater every pregnant women should be equally active which ensure her safe and comfortable delivery. One of our participants viewed:

"Now a day I heard many new advices and words. I have seven babies and this is my eighth pregnancy. I always engage myself at all activities like normal time, but nothing was experienced serious. So I don't believe in the concept that pregnant women should extra care and safety. If a woman avoid household activity, who will do that? Doing work is much better than being scolded by members of husband's family."

\section{Access to Health Services those are closer to pregnant women}

As our studied villages were closer to Sylhet city, they had multiple opportunities to get health supports. Sylhet is a 
metropolitan city where medical services are available. There are three medical colleges, notable number of private clinics and NGO based medical services that can offer medical supports for all segments of population. The forth largest government medical college hospital is located in Sylhet city where most of medical services are free of cost. There are NGO based clinics those offer cheaper medical services targeting disadvantaged population. In addition with those services, Government Union Health Centers are very closer to studied villages. Except private clinics and hospitals, medical expenses are affordable and have easy access for low income groups. Most of our participants are aware about the nature of services offered by those health service centers. However, we found a small number of pregnant women who take advantages of those opportunities. These women are allowed to go outside home alone after consultation with family members mainly husband and mother in-law. They took services like medical check-up and advice of medical doctors from those centers and expressed their mixed observation on services. Few viewed that the services those are offered is good and satisfied with their behavior. Social and family norms, personal perceptions on health related to pregnancy restrict many pregnant women from receiving services from those institutions. One of our participants viewed that:

"I am not allowed to go outside home alone and never went anywhere alone. If my husband or mother in law give permission and any of my husband's family members like my husband, mother in-law, brother in-law or sister in-law is agree to give me company; only then I can go outside. Despite having my personal need and interest to go to physician, I can not go for that obstacle."

Many pregnant women belief that if any pregnant woman goes to hospital, physician will arrange surgical operation for delivery, it will affect the body negatively and large amount of money will be spent. Showing those logic this group prefer to arrange delivery and other complicacies at home traditionally. They also perceive that remembering almighty God and deep trust upon God at the moment of crisis can solve all problems. As one participant mentioned:

"We are five brothers and two sisters. My mother never went to hospital for delivery any baby. We have our own Dai (indigenous midwife) in our locality. Why should I go for doctors? Allah will help us during any emergency. I always depend on His mercy."

\section{How Economic Condition and Religion do affect in receiving Medical Treatment}

A large number of populations in Bangladesh are below the poverty line. On the other hand, the magnitude of poverty in rural area is higher than that of urban centers. This study was conducted in rural areas in which we found that most of the people's earning is poor in comparison to the expenditure for everyday living. Due to having poverty it becomes difficult for many of our participants to continue regular medical treatment and check-up. They observed it as expensive and they have to pay for service which creates pressure on their family resources. That is why they can not arrange expenditure for regular check-up. In some cases they fail to buy medicine recommended by physician. One of our participants appalling statement can clarify the magnitude of this reality,

"My family income is poor, we can not afford three meals daily, we and our children sometimes spend nights with starvation. So how can we spend money for medical purpose during pregnancy?"

Religious restrictions sometimes affect women health behavior. Few of our participants opined that they do not go outside their home during pregnancy as they assume that this shall hamper their privacy that is not accepted by their religious norms. Some also do believe is superstitions in compilation with religion. One of our participants mentioned that,

"During pregnancy I do not go outside. If I go outside people may have a look on me and my personal privacy will be hampered. Keeping physical integrity and privacy is an obligation of our religion. On the other hand our seniors suggested us to avoid crossing river at pregnancy. If anybody cross river for any purpose she and her fetus might be affected by bad spirit. One pregnant woman died last year due to crossing river. As I have to cross river to reach medical center, I do not go there and have no plan to go to outside my home during the whole period of my pregnancy."

Seeking supports from male physician is also restricted by religious norms in rural areas and still few of our participants avoid going medical check-up as it is performed by a male physician. One participant quoted that,

"Our health center is run by a male physician. I know I should go there for regular check-up. But, how can I show my face and allow him to touch my body for medical check-up! Our religion does not permit to do that and that is why I avoid going there. Many women in our village do not visit that health center for the same reason. Once my husband took me a clinic in Sylhet, they have female physician.

\section{Nature of Traditional Healers the Participants Visited}

Faith on traditional healers is in-fact rooted in rural culture in Bangladesh. We found that all of our participants are somehow connected with the link of traditional healers. Muslim clergymen are known as Pir, Fakir and Priest of Mosques. It is believe that these people have close relation with God and they do have special power. As well as they use the religious words, holy books those also have the power of god. Another group of healers offer treatment with the use of barks leafs and roots of different trees commonly 
called as Ayurvedic treatment.

\section{Services provided by Traditional Healers}

Most of the services offered by traditional healers are based on religious faith. Those traditional healers apply magic, give sacred water, oil and holy thread that worn round the arm or waist, amulets containing holy words or a charm against evils that are usually recommended to worn on the arm. They also use winnowed for kicking evil spirit and apply some herbal medicine for common complicacies related to pregnancy. Some healers apply sacred brown sugar to get relief from labor pain. Few clergymen give special holy flower to pregnant woman and it is recommended that she will have it with water just after starting labor pain and the power of flower will reduce pain during delivery and safe delivery will be ensured. Few healers use leaf-made necklace for reducing headeque during pregnancy. One of our respondents described how she was cured by the treatment of traditional healer,

"During my first pregnancy, I consulted with traditional healer who is pious and has special power. He gave me sacred water, oil, holy thread and amulets. All of these were very effective and almighty God gave me a healthy boy baby. This time I am under his treatment. This time I was experiencing serious headache and he gave me a leaf-made necklace which is giving excellent result. The healer will also give me holy flower for reducing my labor pain. All of my family members have deep trust upon his treatment."

Participants also used to go to Darghah (Shrine of Hazrat Shahjalal) to get help during any crisis. They offer food and money to the Khadem (custodian of the shrine) to get favour and help from this holly man. As one participant mentioned:

"When I get pregnant I used to go to Shahjalal's Majar (Shrine of Hazrat Shahjalal) pay some money to the Khadem (custodian). He (Khadem) give me a special thread to put it on my arm. I never face any complicacy during any delivery."

\section{Why do Pregnant Women go to Traditional Healers?}

In the study area, seeking care from traditional healers such as Moulovi, herbalist, and Kabiraj is common. Seeking care from traditional healers is encouraged because of easy access, a closer relationship and a similar cultural understanding of the body. The participant mentioned they felt more comfortable asking questions and talking about their illness and treatment with someone who shared the same cultural heritage, who spoke their native language, and were female. One participant explained,

"The Kabiraj is our own people with whom we can share our problems freely. We can go to his home any time and he is always cordial. As he lives in our area, he knows all of us and we can talk anything to him regarding our problems. He can understand our problems easily and can provide appropriate assistance. That is why, we seek care from him."
All of our participants opined that the pregnant woman should visit both traditional healers and medical doctors as their role is different. People in rural areas do believe in superstitions and according to them, those can be removed only by the treatment of traditional healers or by religious clergymen. According to our participants, during pregnancy there is a risk to be attacked by invisible spirits and ghosts. If a pregnant woman is attacked by any evil and invisible spirit traditional healers can identify the case. But a physician can not understand and therefore they need supports from those people especially the religious clergymen as they offered treatment based on holy words those have power of god. Our participants viewed that a kind of bad wind and bad eyesight have harmful affects on pregnant women. However, they failed to identify the type of bad look or wind. They informed that people go to traditional healers in order to protect pregnant women from those problems that are not possible to treat by medical doctors. One of our participants told that,

"Sometimes the sacred water from religious clergyman is more effective that a physician's treatment if we do have trust upon it. As it has Gods blessing, we get positive result."

Another participant opined,

"Mental problems may not be removed by physician but it can easily be removed by religious clergymen. If you want to stop bad dreaming, you need traditional healers support. If you want to stop the affects of bad eyesight or the affects of bad invisible spirit, you will need some treatment that can only be offered by traditional healers."

Due to poverty many also go to traditional healers as their treatment is less expensive and in some cases free of cost. One of our participants informed that,

"My family is poor and I can not afford expensive treatment. If I go to Kabiraj or Moulovi, they usually do not take money from me as they know about my financial condition. They take few amounts (taka ten to twenty) occasionally if I need medicine."

Sometimes family expectation force pregnant women for seeking health supports from traditional healers. Few of our participants informed that their mother and mothers in- laws suggest them to go to traditional healers and they followed their suggestion. Few also opined that pregnant woman should go to both medical doctor and traditional healers as she does not know which one will work.

\section{How do society people perceive health complicacies during pregnancy?}

In rural Bangladesh still pregnancy is considered as natural process and which goes with some complicacies those are as part of biological process. We found the same perception in our study area. Participants viewed that their community people do not consider pregnancy related complicacies as important. Rather, they suggest tolerating 
complicacies and encouraging pregnant women for avoiding treatment or check-up. One of our participant's anecdotes reveals the reality of community people's perception,

"Many people of our society observe all pregnancy related complicacies as natural. They suggest that we should not go to medical professionals if there is no serious problem. Spending money for this purpose is worthless."

Another participant told,

"Our community people view that a pregnant woman can cross the whole period without complicacies if she carefully follows the guideline and suggestions of senior and experienced women. Traditional Birth Attendant's (TBA) advice is enough for good health during pregnancy. If TBA fails then one should go to hospital or clinic."

Sometimes this type of perception contributes serious affects in the physical wellbeing of pregnant women. In this connection, one of our participants shared her experience,

"In our community, sometimes a TBA keeps on try for normal delivery at home for a longer time. After starting labor pain they start process for normal delivery and continue up to two or three days. Once all of their efforts fail, family members shift the pregnant woman at hospital. As its result many pregnant women in our community died or they have given birth dead babies."

\section{Social Perception on Receiving Medical Treatment and Regular check-up during Pregnancy}

We found multiple views on the reliance of receiving medical support during pregnancy. Though few people in the society consider it as personal matter, many views that as pregnancy is a natural process, a pregnant woman should not go to hospital or clinic, rather she should remember the God by performing regular prayer so that almighty helps her at any physical complicacy. One should go to hospital only when she is sick physically. One of our participant's views can be presented below:

"Our seniors say that -now a days girls have no patience, they go to doctor even for a negligible reason. Even they are not ashamed from going to a male medical doctor for regular check-up. On the other hand older women do not appear before an unknown male."

On the other hand participants also mentioned that things are getting changed and community show positive attitude towards regular medical check-up during pregnancy and opined it as the result of massive health consciousness among people. As one participant mentioned:

"My mother in law told me to go for hospital for regular check up. She told me that now a days you have clinic very close to our home. You should take the advantages of modern age."

\section{Do the Participants follow Special Instruction during Pregnancy?}

Most of our participants are found to be reluctant in following special medical instruction during pregnancy. Few follow some instruction of physicians like taking additional food and careful movement. However, a notable number of participants follow traditional rules and regulations during pregnancy those are mainly prescribed by senior women in the family, traditional healers and clergymen. Almost all of those instructions had scientific base and even in many cases those can cause serious harm. One of our participants told that she is suggested taking less food during pregnancy by female members at her family. The logic behind this suggestion that once a pregnant woman take less food during pregnancy, growth of her baby shall be restricted and as its result she will have less painful and easy delivery. Few do not take eggs during pregnancy after being suggested by spiritual healer.

\section{Future hope and expectation}

Almost all of our participants opined that taking medical support during pregnancy can safe the life of both mother and the infant and that is why it should have provisions in health centers so that they may have easy access as per their cultural and religious norms. As financial condition affects regular medical supports for pregnant women, they suggested for opening opportunities so that people can get pregnancy related medical support free of cost or with a minimum cost. Our participants expects that medical supports those are offered by NGO clinics and government health centers should be ensured with sufficient number of experienced medical professional. They opined that if medical check-up and medicine is free of cost for pregnant women, most of the women shall be encouraged to go to medical centers. They also suggested that health worker or other staffs of health centers or government directly can arrange massive health awareness building program for pregnant women. This can increase the number of pregnant women who go to medical professionals for regular check-up. They expect that every Uninion health centers should have arrangement for safe delivery with sufficient infrastructure and medical professions.

\section{Overall Discussion and Concluding Remarks}

Maternal and reproductive health is directly linked with the wellbeing of women and children. Considering this as important, the government of Bangladesh has taken series of activities. Despite having financial crisis government has arranged many of antenatal and postnatal services free of 
cost and established health centers at rural areas. It was expected that those initiatives will bring remarkable progress in improving overall health conditions of women and children. Although progress has been made, still it is not fully satisfactory. The findings of present research reveals that only infrastructural development can not ensure the success in health sector, changing people's behavior is significant for utilizing those supports and services. We conducted this study in three villages and all of those localities have good connectivity with urban centers and they have opportunity to get easy access to government and NGO health centers. However, all of the pregnant women in those villages are not conscious about pregnancy related health and physical wellbeing. They also have poor understanding about the risk and threats of this stage. Many still rely upon traditional healers and avoid visiting hospitals or physicians regularly. Majority of the pregnant women try to minimize problems with the consultation of seniors and traditional healers. Once all efforts fail, they visit hospitals and as its results many of them experienced serious health complicacies. The rate of receiving medical support is found to be lower that of national statistics in Bangladesh. Massive poverty, socio-cultural norms and religious believe affects the health behavior of pregnant women at our research area. Few of our participants pointed out the quality and cost of services those discouraged them from going medical treatment from existing health supports in their locality. Non-availability of delivery services in rural health centers sometimes encouraged women to avoid the services those are located closer to their community and they prioritized such service that can ensure modern and emergency treatment. Considering those issues, strategies should be undertaken in a way so that government can achieve target that have been mentioned the in the Millennium Development Goal.

\section{REFERENCES}

Ahmed S. M., Tomson, G. Petzold M. \& Kabir Z. N. (2005). "Socioeconomic status overrides age and gender in determining health seeking behaviour in rural Bangladesh". Bulletin of the World Health Organisation 83: 109-117

Atuyambe, Lynn et al. (2008). “Adolescent and adult first time mothers' health seeking practices during pregnancy and early motherhood in Wakiso district, central Uganda. Reproductive Health. 5: 13.

Bangladesh Bureau of Statistics, BBS. (2002). Statistical Pocketbook of Bangladesh 2001. Dhaka: Bangladesh Bureau of Statistics, Planning Division, Ministry of Planning, Government of the People's Republic of Bangladesh.

Batliwala, S. (1994). "The Meaning of Women's Empowerment: New Concepts from Action", in G. Sen, A. Germain, and L. C. Chen (eds.), Population Policies Reconsidered. London: Harvard University Press.
Becher H, Muller O, Jahn A, Gbangou A, Kynast-Wolf G, Kouyate B. (2004). Risk factors of infant and child mortality in rural Burkina Faso. Bulletin of the World Health Organization. 2004;82:265-273.

Biswas, Priti et al. (2006). "Dynamics of Health Care Seeking Behaviour of Elderly People in Rural Bangladesh" International Journal of Ageing and Later Life, 2006 1(1): 69-89.

Hossen, M. A. \& Westhues, A. (2011). "Rural women Access to Health Care in Bangladesh: Swimming Against the tide?" Social work in Public Health, 26(30) 278-293.

Hossen M.A. \& Westhues, A. (2011) The Medicine that might kill the patient: Structural adjustment and its impacts on health care in Bangladesh. Social Work in Public Health 26 (5) 125-140.

Kabeer, N. (1999). "Resources, Agency, Achievements: Reflections on the Measurement of Women's Empowerment", Development and Change. Vol.30 (3) pp. 435- 64.

Kibria, N. (1995). "Culture, Social Class and Social Control in the Lives of Garments Workers in Bangladesh" Gender and Society, 9 , 289-309.

Koenig, Michael A. and Others (2007). "Maternal Health and Care-Seeking Behavior in Bangladesh: Findings from a National Survey". International Family Planning Perspectives, Vol. 33, No. 2 (Jun., 2007), pp. 75-82

Mayor S. Pregnancy and childbirth are leading causes of death in teenage girls in developing countries. BMJ (Clinical research ed). 2004;328:1152. doi: 10.1136/bmj.328.7449.1152-a.

Nath, D. K. (2008). Health Policy for achieving MDG's The Daily Star, 21 April. Accessed from

http://www.thedailystar.net/story.php?nid=32985 (on April $30,208)$.

Nuruzzaman, M. H. (2009). "Affecting Maternal Health Services Utilization Married Adolescents And Their Use Of Maternal Health Services In Bangladesh". Internet Journal of Health, 2009. In http://www.britannica.com/bps/additionalcontent/18/36122546 accessed in December 27, 2009.

Magadi M, Diamond I, Madise N. (2001). Analysis of factors associated with maternal mortality in Kenyan hospitals. Journal of biosocial science. 2001;33:375-389. doi: $10.1017 / \mathrm{S} 0021932001003753$.

Osmani, O.H. (2010). Towards Achieving the right to Health: The case of Bangladesh. Bangladesh Development Studies XXXIII (1\&2) 25-90.

Reynolds HW, Wong EL, Tucker H. (2006). Adolescents' use of maternal and child health services in developing countries. International family planning perspectives. 2006;32:6-16. doi: $10.1363 / 3200606$.

LeGrand TK, Mbacke CS. (1993). Teenage pregnancy and child health in the urban Sahel. Studies in family planning. 1993;24:137-149. doi: 10.2307/2939229.

Reza, M. Hasan and Ahmmed Faisal. (2009). "Structural Social Work and the Compatibility of NGO Approaches: A Case Analysis of Bangladesh Rural Advancement Committee" International Journal of Social Welfare, 18, 173-182.

United Nations Development Programme, UNDP (2003). Human Development Report 2003. Oxford: Oxford University Press. 
Vol.3. No.2 April, 2015, pp. 90-99

World Bank (2002). Poverty in Bangladesh: Building on Progress. World Bank and Asian Development Bank. Poverty Reduction and Economic Management Sector Unit, South Asia Region: The World Bank (Report No. 24299-BD).
Young, K. (1988). Gender and Development: A Rational Approach. Oxford: Oxford University Press. 